\title{
Comparison of improved range of motion between cam-type femoroacetabular impingement and borderline developmental dysplasia of the hip -evaluation by virtual osteochondroplasty using computer simulation-
}

So Kubota, Yutaka Inaba*, Naomi Kobayashi, Hyonmin Choe, Taro Tezuka and Tomoyuki Saito

\begin{abstract}
Background: While cam resection is essential to achieve a good clinical result with respect to femoroacetabular impingement (FAI), it is unclear whether it should also be performed in cases of borderline developmental dysplasia of the hip (DDH) with a cam deformity. The aim of this study was to evaluate improvements in range of motion (ROM) in cases of cam-type FAl and borderline DDH after virtual osteochondroplasty using a computer impingement simulation.

Methods: Thirty-eight symptomatic hips in 31 patients ( 11 male and 20 female) diagnosed with cam-type FAl or borderline DDH were analyzed. There were divided into a cam-type FAl group (cam-FAl group: 15 hips), borderline DDH without cam group (DDH W/O cam group: 12 hips), and borderline DDH with cam group (DDH W/ cam group: 11 hips). The bony impingement point on the femoral head-neck junction at $90^{\circ}$ flexion and maximum internal rotation of the hip joint was identified using ZedHip ${ }^{\circledR}$ software. Virtual osteochondroplasty of the impingement point was then performed in all cases. The maximum flexion angle and maximum internal rotation angle at $90^{\circ}$ flexion were measured before and after virtual osteochondroplasty at two resection ranges (i.e., slight and sufficient).

Results: The mean improvement in the internal rotation angle in the DDH W/ cam group after slight resection was significantly greater than that in the DDH W/O cam group $(P=0.046)$. Furthermore, the mean improvement in the internal rotation angle in the DDH W/ cam and cam-FAl groups after sufficient resection was significantly greater than that in the DDH W/O cam group (DDH W/ cam vs DDH W/O cam: $P=0.002$, cam-FAl vs DDH W/O cam: $P=0.043$ ).

Conclusion: Virtual osteochondroplasty resulted in a significant improvement in internal rotation angle in DDH W/ cam group but not in DDH W/O cam group. Thus, borderline DDH cases with cam deformity may be better to consider performing osteochondroplasty.
\end{abstract}

Keywords: Femoroacetabular impingement, Borderline developmental dysplasia of the hip, Impingement simulation, Range of motion

* Correspondence: yute0131@med.yokohama-cu.ac.jp

Department of Orthopaedic Surgery, Yokohama City University, 3-9Fukuura,

Kanazawa-ku, Yokohama, Kanagawa 236-0004, Japan 


\section{Background}

Femoroacetabular impingement (FAI) is an important cause of hip pain and subsequent osteoarthritis [1]. It is caused by an anatomical abnormality that results in mechanical impingement between the acetabular rim and the femoral head-neck junction during flexion and internal rotation of the hip $[2,3]$. A major factor is cam deformity of the femur, which is characterized by an aspherical femoral head and bony bump formation at the femoral head-neck junction, which reduces femoral head-neck offset $[2,3]$. FAI causes hip pain during squatting or deep flexion and may therefore reduce range of motion (ROM) at that joint [4]. These morphological abnormalities can be corrected by osteochondroplasty, which releases the bony impingement and improves ROM.

Developmental dysplasia of the hip (DDH) also causes hip pain, and has an etiological factor in the development of hip osteoarthritis $[5,6]$. Its essential concept is that a biomechanical abnormality, joint incongruity, or decreased joint contact area may increase mechanical stress at the acetabular rim [6]. Although the basic pathophysiology of DDH is different from that of FAI, there are cases in which borderline DDH co-exists with a cam deformity $[7,8]$. While cam resection is essential to achieve a good clinical result with respect to FAI [9, 10], it is unclear whether it should also be performed in cases of borderline DDH. In this regard, computer simulated virtual osteochondroplasty may provide the answer from the point of view of improvement in ROM.

The aim of this study was to investigate improvement in ROM after virtual hip osteochondroplasty using computer impingement simulation models for cam type FAI, borderline DDH with cam deformity, and borderline DDH without cam deformity.

We hypothesized that borderline DDH with cam deformity and cam-type FAI cases would demonstrate similar and significant improvement in ROM after virtual osteochondroplasty.

\section{Methods}

This study was approved by the institutional review board at Yokohama City University. In total, 38 symptomatic hips in 31 patients (11 male and 20 female) diagnosed with cam-type FAI or borderline DDH by plain radiography were enrolled. The mean age of the patients was $47.8 \pm 13.0$ years (range, 21-74 years). The anterior impingement test was positive in all 38 hips. Computed tomography $(\mathrm{CT})$ and radiographic evaluation were performed during the same period (within 3 months) in all cases.

\section{Radiographic evaluation}

The lateral center-edge (CE) angle, Tönnis grade and crossover sign were measured on an antero-posterior
(A-P) view of the pelvis. The alpha angle was measured on a cross table lateral view of the hip joint. The measurement procedure was standardized in the picture archiving and communication system.

\section{Definition of cam-type FAI and borderline DDH}

Cam-type FAI was defined as an alpha angle $\geq 55^{\circ}[11,12]$ and a CE angle $\geq 25^{\circ}[13,14]$. Borderline DDH was defined as a CE angle between 20 and $24^{\circ}$ [13, 15]. Borderline DDH with cam deformity was defined as a combination of borderline DDH $\left(20 \leq \mathrm{CE}\right.$ angle $\left.<25^{\circ}\right)$ and cam (alpha angle $\geq 55^{\circ}$ ). Thus, the 38 hips were assigned to three groups: a cam-type FAI group (cam-FAI group; 15 hips), a borderline DDH without cam deformity group (DDH W/O cam group; 12 hips), and a borderline $\mathrm{DDH}$ with cam deformity group (DDH W/ cam group; 11 hips). Pincer-type FAI cases (CE angle $>40^{\circ}$ ) [16], DDH with a CE angle of $<20^{\circ}$, or osteoarthritic changes with a Tönnis grade $\geq 2$ were excluded.

\section{Computed tomography}

CT scans (Sensation16; Siemens AG, Erlangen, Germany) of the pelvis and femurs of all patients were acquired using the following scanner settings: $140 \mathrm{kV}$ and $300 \mathrm{~mA}$; slice thickness, $1.5 \mathrm{~mm}$; pixel resolution, $512 \times 512$; voxel size, $0.70 \times 0.70 \times 1.5 \mathrm{~mm}$.

\section{Computer simulated impingement analysis}

ZedHip $^{\oplus}$ (LEXI Co., Ltd., Tokyo, Japan) software was used to perform impingement simulation analysis. Digital imaging and communication in medicine (DICOM) data for each patient were transferred to ZedHip ${ }^{\oplus}$, and three-dimensional (3D) simulation models of the pelvis and femur were constructed. The functional pelvic plane in a supine position was used as the pelvic plane reference. To set the femoral plane reference, the femoral head center was defined by assigning four reference points. The axis was set using two reference points: the head center and the mid-point between the medial and lateral epicondyles. Then, the pelvis and femur were segmented. The bony impingement point on the femoral head-neck junction at $90^{\circ}$ flexion and maximum internal rotation of the hip joint was then identified (Fig. 1). The bony impingement was contact point between the acetabular rim and the femoral head-neck junction at the terminal point of the impingement simulation. If the impingement point appeared below $90^{\circ}$ of flexion, the case was excluded. The impingement region of interests was defined into 2 regions (i.e., proximal region and distal region) in A-P view of the hip joint [17], and difference in the distribution of the impingement point was evaluated between cam-FAI and DDH W/ cam groups.

Virtual resection of the impingement point was then performed by the same investigator using ZedHip ${ }^{\oplus}$. The 

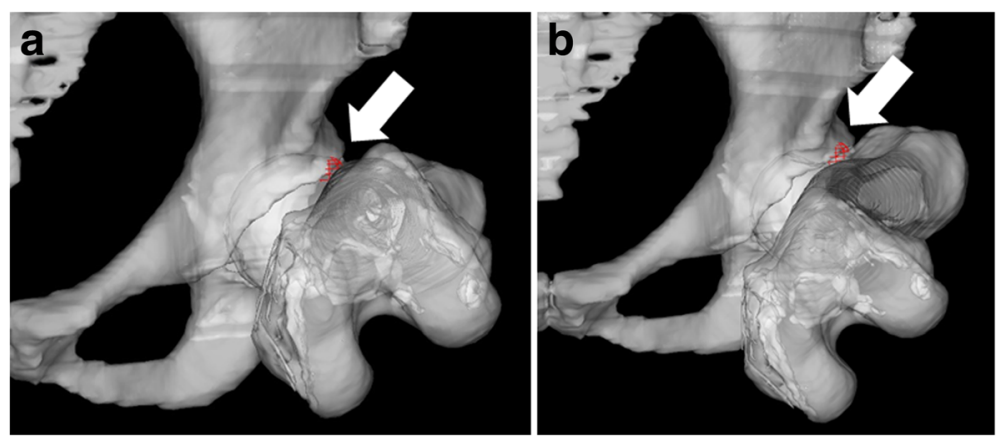

Fig. 1 Pre- and postoperative 3D images of the impingement simulation Impingement points are identified by arrows. The impingement point at the femoral head-neck junction at $90^{\circ}$ flexion and maximum internal rotation of the hip joint is shown preoperatively (a) and postoperatively (b)

center of resection area was decided based on the impingement point by ZedHip ${ }^{\circ}$. Figure 2 shows the defined area of resection based on each impingement point. Because the resection depth for cam deformity would typically be $4-8 \mathrm{~mm}[18]$, two different versions were modeled: slight resection at a depth of $4 \mathrm{~mm}$ and sufficient resection at a depth of $8 \mathrm{~mm}$. The width of the resected area in a horizontal slice was modeled as slight $(8 \mathrm{~mm})$ and sufficient $(16 \mathrm{~mm})$. The length of the resection was standardized at $15 \mathrm{~mm}$ ( $1.5 \mathrm{~mm}$ slice $\times 10$ slices $)$ in each axial image [19]. The edge of each resection area was trimmed smoothly to simulate clinical situation.

The maximum flexion angle and maximum internal rotation angle at $90^{\circ}$ flexion was measured both before and after virtual osteochondroplasty using ZedHip ${ }^{\circ}$ using each resection model (i.e., slight resection and sufficient resection) for cam-type FAI, borderline DDH with cam deformity, and borderline DDH without cam deformity cases.

\section{Statistical analysis}

The demographic data and imaging study results for all groups were evaluated using one-way factorial analysis of variance, as were the maximum flexion angle and maximum internal rotation angle at $90^{\circ}$ flexion before virtual osteochondroplasty and improvements in the angle of maximum flexion angle and maximum internal rotation at $90^{\circ}$ flexion. Difference in the distribution of the impingement point was evaluated using contingency table. Intraobserver reliability was calculated using intraclass correlation coefficients and their 95\% confidence intervals (CIs) to assess the reliability of the improvement in the internal rotation angle at each resection models. $P$ values $<0.05$ were considered statistically significant. All statistical analyses were performed using dedicated statistical analysis software (SPSS 16.0; IBM Corp., Armonk, NY, USA).

\section{Results}

The demographic data for the three groups are presented in the Table 1 . The mean body mass index (BMI) in the cam-FAI group was significantly higher than that in the DDH W/O cam group $(P=0.012)$. positive crossover sign was seen in 9 hips out of 38 hips, and it was seen most in cam-type FAI group.

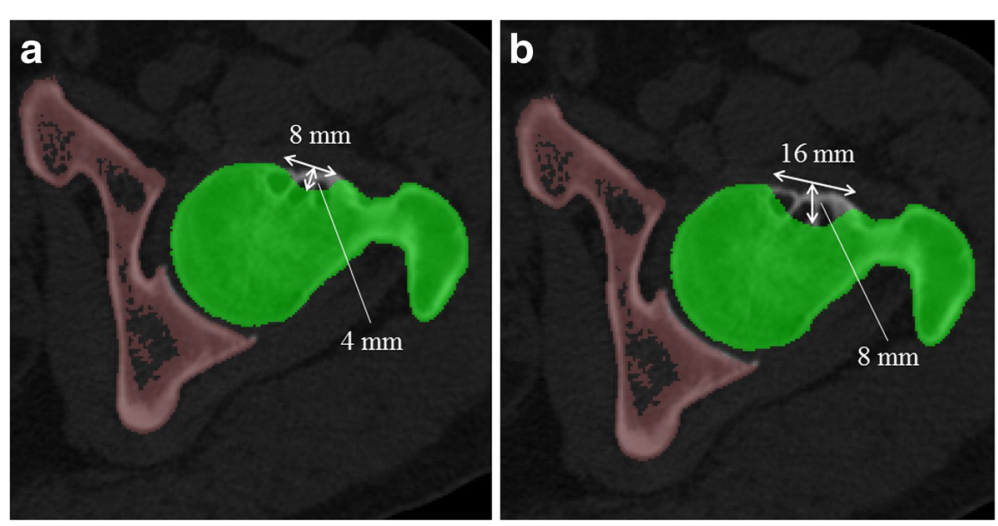

Fig. 2 The virtual resection of the impingement point The depth and width of the resection in the horizontal slice and the vertical resection length around the impingement point were standardized (i.e., slight resection (a), sufficient resection (b)) 
Table 1 Demographic data for the cam-FAl, DDH W/ cam, and DDH W/O cam groups

\begin{tabular}{llll}
\hline & $\begin{array}{l}\text { Cam-FAl } \\
(n=15)\end{array}$ & $\begin{array}{l}\text { DDH W/ cam } \\
(n=11)\end{array}$ & $\begin{array}{l}\text { DDH W/O cam } \\
(n=12)\end{array}$ \\
\hline Sex (male / female) & $11 / 4$ & $1 / 10$ & $1 / 11$ \\
Age (mean \pm SD) & $48.7 \pm 12.5$ & $49.9 \pm 11.9$ & $44.8 \pm 15.1$ \\
BMI (mean \pm SD) & $23.5 \pm 3.2$ & $22.1 \pm 2.5$ & $20.4 \pm 2.2$ \\
CE angle (mean \pm SD) & $32.3 \pm 4.2$ & $22.0 \pm 1.5$ & $21.7 \pm 1.7$ \\
alpha angle (mean \pm SD) & $65.7 \pm 7.6$ & $63.6 \pm 6.1$ & $49.5 \pm 3.6$ \\
Tönnis grade (0 / 1) & $10 / 5$ & $7 / 4$ & $10 / 2$ \\
$\begin{array}{l}\text { Crossover sign } \\
\text { (positive/ negative) }\end{array}$ & $6 / 9$ & $2 / 9$ & $1 / 11$ \\
\hline BM body mas index, CE cente-eg & & &
\end{tabular}

$B M I$ body mass index, $C E$ center-edge, $S D$ standard deviation

The differences in the maximum flexion angle prior to virtual osteochondroplasty are shown in Fig. 3. The mean maximum flexion angle in the cam-FAI group was $113.1 \pm 6.9^{\circ}$, whereas that in the DDH W/ cam and DDH $\mathrm{W} / \mathrm{O}$ cam groups was $122.5 \pm 14.7^{\circ}$ and $132.8 \pm 9.0^{\circ}$, respectively. The mean maximum flexion angle in the $\mathrm{DDH} \mathrm{W} / \mathrm{O}$ cam group was significantly greater than that in the cam-FAI group $(P=0.001)$. Differences in the maximum internal rotation angle prior to virtual osteochondroplasty are shown in Fig. 4. The mean maximum internal rotation angle in the cam-FAI group was $25.8 \pm 11.8^{\circ}$, whereas that in the $\mathrm{DDH} \mathrm{W} /$ cam and $\mathrm{DDH} \mathrm{W} / \mathrm{O}$ cam groups was $38.9 \pm 19.9^{\circ}$ and $62.4 \pm 15.0^{\circ}$, respectively. The mean maximum internal rotation angle in the $\mathrm{DDH} \mathrm{W} / \mathrm{O}$ cam group was significantly greater than that in the cam-FAI $(P=0.001)$ and $\mathrm{DDH} \mathrm{W} / \mathrm{cam}$ groups $(P=0.002)$.
The impingement region in the cam-FAI group was distributed to 9 hips in the proximal region, and 6 hips in the distal region. The impingement region in the DDH W/ cam group was distributed to 8 hips in the proximal region, and 3 hips in the distal region. There was no significant difference in the distribution of the impingement point between cam-FAI and DDH W/ cam groups $(P=0.68)$.

The mean improvement in the flexion angle in the cam-FAI group after slight resection was $0.3 \pm 1.0^{\circ}$, whereas that in the DDH W/ cam and DDH W/O cam groups was $0.6 \pm 1.3^{\circ}$ and $0.0 \pm 0.0^{\circ}$, respectively. The mean improvement in the flexion angle in the cam-FAI group after sufficient resection was $0.4 \pm 1.5^{\circ}$, whereas that in the $\mathrm{DDH} \mathrm{W} / \mathrm{cam}$ and $\mathrm{DDH} \mathrm{W} / \mathrm{O}$ cam groups was $1.2 \pm 2.0^{\circ}$ and $0.2 \pm 0.6^{\circ}$, respectively. There was no significant difference in any of these values between the three groups, regardless of resection type. The mean improvement in the internal rotation angle in each of the three groups after virtual resection is shown in Fig. 5. The improvement in the cam-FAI group after slight resection was $3.3 \pm 2.1^{\circ}$, whereas that in the DDH W/ cam and $\mathrm{DDH} \mathrm{W} / \mathrm{O}$ cam groups was $4.7 \pm 5.3^{\circ}$ and $1.4 \pm 1.3^{\circ}$, respectively. The mean improvement in the internal rotation angle after slight resection was significantly greater in the DDH W/ cam group than in the DDH W/ O cam group $(P=0.046)$; however, there was no significant difference between the cam-FAI and DDH W/O cam groups. The mean improvement in the internal rotation angle in the cam-FAI group after sufficient resection was $7.4 \pm 3.9^{\circ}$, whereas that in the $\mathrm{DDH} \mathrm{W} / \mathrm{cam}$ group and $\mathrm{DDH} \mathrm{W} / \mathrm{O}$ cam groups was $10.0 \pm 5.9^{\circ}$ and

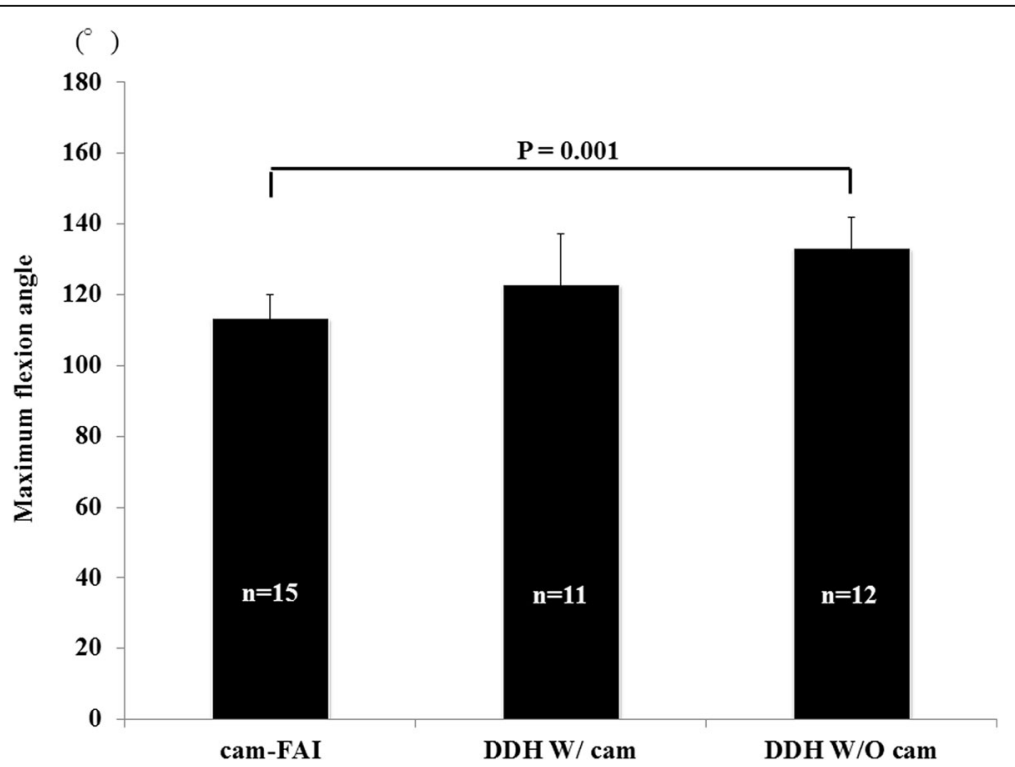

Fig. 3 Maximum flexion angle in the three groups before virtual osteochondroplasty The mean maximum flexion angle in the DDH W/O cam group was significantly greater than that in the cam-FAl FAl group $(P=0.001)$ 


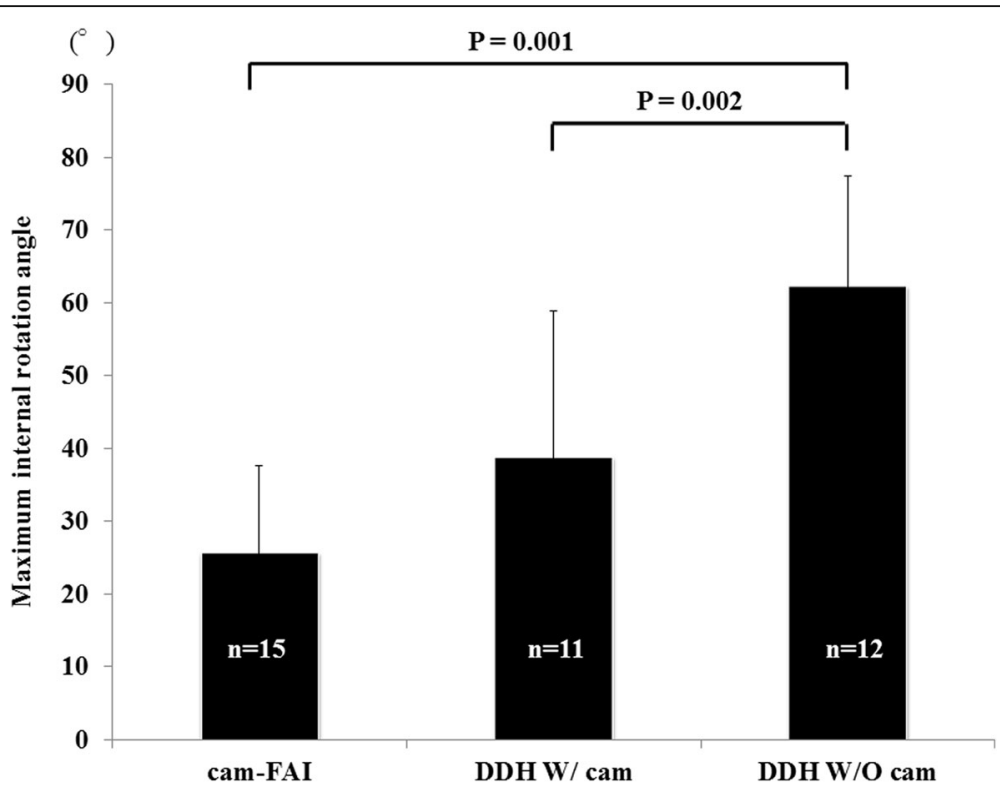

Fig. 4 Maximum internal rotation angle in the three groups before virtual osteochondroplasty The mean maximum internal rotation angle in the $\mathrm{DDH}$ W/O cam group was significantly greater than that in the cam-FAl $(P=0.001)$ and DDH W/ cam groups $(P=0.002)$

$3.3 \pm 2.5^{\circ}$, respectively. The mean improvement in the internal rotation angle in the $\mathrm{DDH} \mathrm{W} / \mathrm{cam}$ group after sufficient resection was significantly greater than that in the DDH W/O cam group $(P=0.002)$, as was that in the cam-FAI group $(P=0.043)$. There was no significant difference between the cam-FAI and DDH W/ cam groups in the improved internal rotation angle regardless of resection type, however, that in the DDH W/ cam group was tended to show more improvement than cam-FAI group for both slight and sufficient resections (Fig. 6).

In assessing the reliability of measuring the improvement in the internal rotation angle by computer simulation, intraobserver reliability was 0.917 (95\% CIs, $0.792-0.969)$ at slight resection, and that was 0.828 (95\% CIs, 0.594-0.933) at sufficient resection, both showing good reliability.

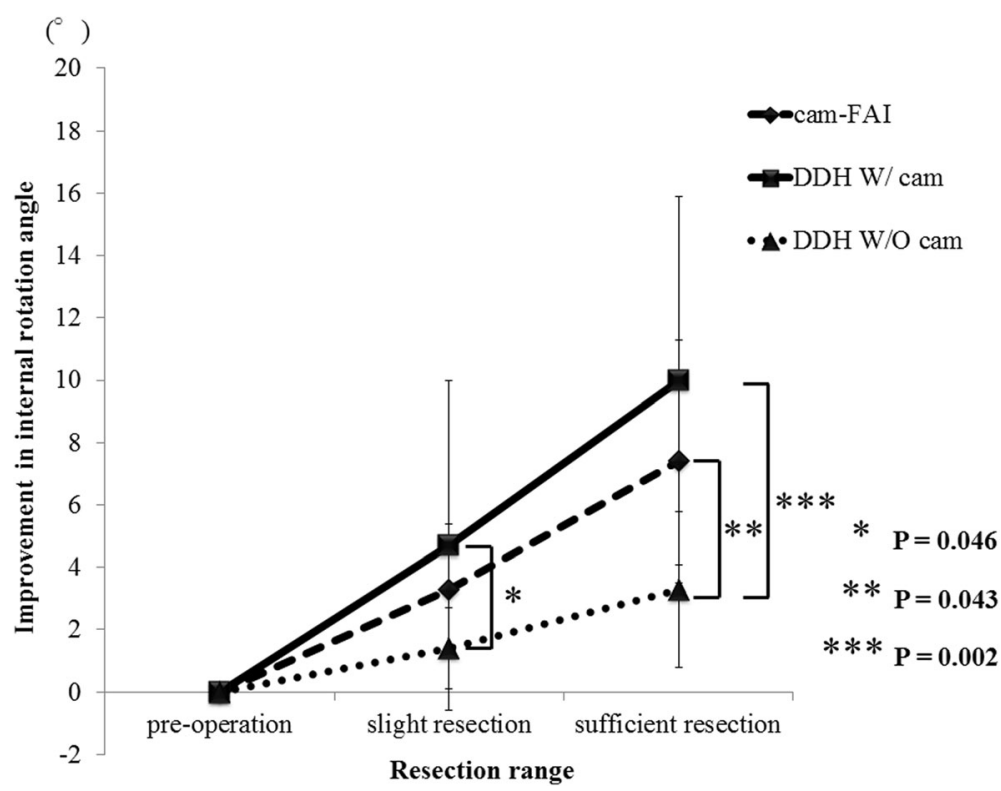

Fig. 5 Improvement in the internal rotation angle after each type of resection The mean improvement in the internal rotation angle in the DDH W/ cam group after slight resection was significantly greater than that in the DDH W/O cam group $(P=0.046)$, as was that after sufficient resection $(P=0.002)$. The improvement in the cam-FAl group was significantly greater than that in the DDH W/O cam group $(P=0.043)$ 

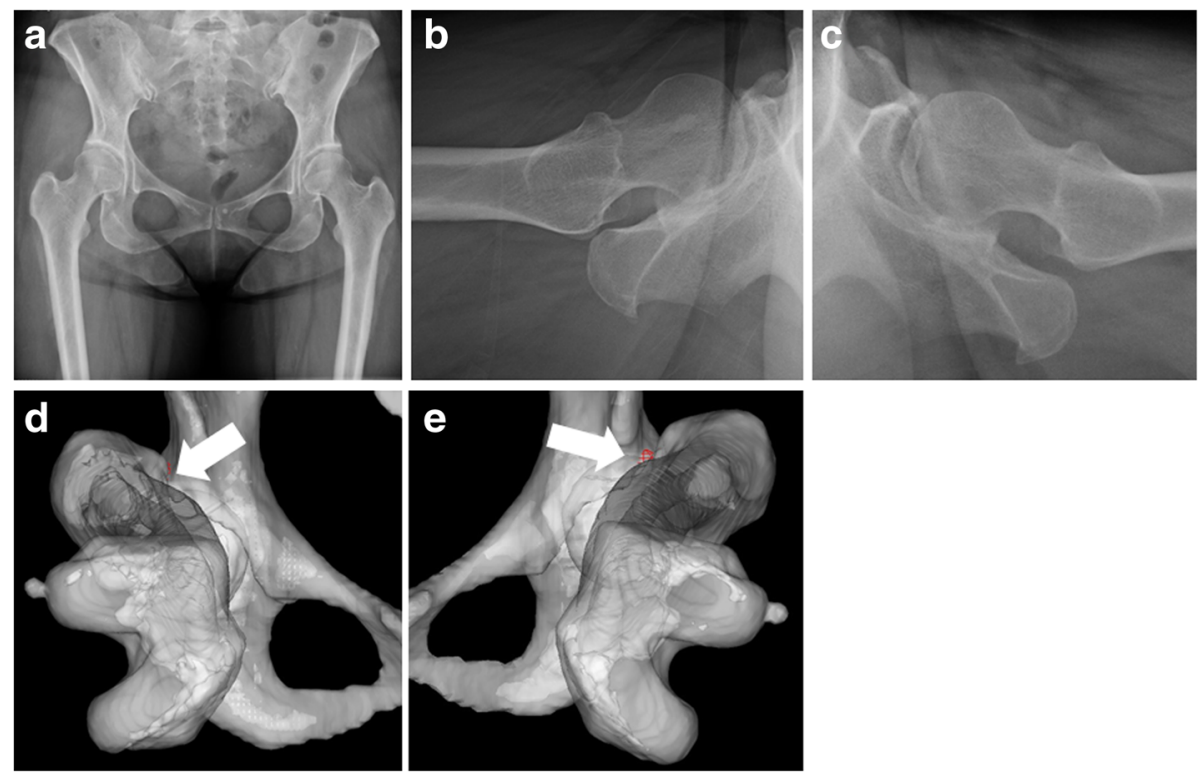

Fig. 6 A representative case of borderline DDH These images are of a 47-year-old woman with borderline DDH with cam deformity in the right hip and borderline DDH without cam deformity in the left hip. The CE angle in the right hip was $21^{\circ}$ and that in the left was $24^{\circ}$ (a). The alpha angle in the right hip was $67^{\circ}$ (b) and that in the left was $51^{\circ}$ (c). Impingement points are identified by arrows (d, e). The preoperative maximum internal rotation angle for both hip joints was $49^{\circ}$. The internal rotation angle in the right hip after slight resection was $53^{\circ}$, whereas that after sufficient resection was $65^{\circ}(\mathbf{d})$. The final improvement in the internal rotation angle of the right hip joint was $16^{\circ}$. However, the internal rotation angle in the left hip after sufficient resection was $52^{\circ}$ (e). Thus, the final improvement in the internal rotation angle of the left hip joint was $3^{\circ}$

\section{Discussion}

Here, we demonstrated that patients with borderline DDH with cam and cam-type FAI showed similar and significant improvement in the internal rotation angle after virtual osteochondroplasty; however, the procedure was not effective for those with borderline DDH without cam. The clinical implication is that it may be better to consider performing osteochodroplasty even in borderline DDH with cam deformity. This is the first study to use computer simulation analysis to examine the effect of cam osteochondroplasty in cases of borderline DDH with cam deformity. In fact, there was no significant difference of pre-operative internal rotation angle between cam-FAI and DDH W/ cam groups. Although preoperative internal rotation angle between DDH W/ cam group seems to be good enough to avoid impingement, the virtual osteochondroplasty resulted in the most improvement in three groups.

Several studies have performed virtual resection of cam lesions using 3D finite element models and computer simulations. Alonso-Rasgado et al. [18] reported that, to reduce the risk of femoral neck fracture, the resection depth should be $<10 \mathrm{~mm}$ or $1 / 3$ the diameter of the neck, whereas Rothenfluh et al. [19] reported that the depth of the resection should be no more than $20 \%$ of the diameter of the femoral neck, and that the resection length should be no more than $20 \mathrm{~mm}$. The main aim of these studies was to use 3D finite element analysis to measure mechanical strength after virtual osteochondroplasty. Bedi et al. [20] used computer simulation models to examine improvements in ROM after performing virtual cam and pincer resection for FAI. While virtual osteochondroplasty at defined regions of impingement resulted in a significant improvement in both hip flexion and internal rotation angle in the eight FAI cases examined, no patients with borderline DDH were included. Nevertheless, these previous simulation studies using virtual osteochondroplasty showed that computer simulation methods have an important role to play in predicting surgical outcome. We believe that the novelty of the present study is the finding of differences in surgical outcome, i.e., improved ROM after virtual osteochondroplasty, for patients with one of three different conditions: cam-type FAI, borderline DDH, and especially borderline DDH with cam deformity.

Previous studies examined clinical results after hip arthroscopy in cases of DDH [13, 21-23]. Byrd et al. [13] and Jayasekera $\mathrm{N}$ et al. [22] reported satisfactory results, even in the presence of dysplasia. Similarly, Fukui et al. [21] reported that arthroscopy of the hip can be successful in young patients with mild to moderate DDH or FAI. However, Uchida et al. [23] reported a clinical failure rate of $32.1 \%$ when treating patients with DDH. Ida et al. [7] reported that $40 \%$ of patients with $\mathrm{DDH}$ showed radiographic evidence of cam deformity, and that significantly more patients in the $\mathrm{DDH}$ with 
cam deformity group than in the DDH alone group had a positive preoperative anterior impingement test. Paliobeis et al. [8] reported that $47 \%$ of patients with FAI showed radiographic evidence of dysplasia. Thus, co-existence of borderline DDH with cam deformity appears certain. Based on the results presented herein, cam osteochondroplasty may be an effective treatment for cases of borderline DDH with cam deformity, even if they undergo only slight resection, whereas cases of cam-type FAI should undergo sufficient resection. By contrast, the procedure would appear to be ineffective for those with borderline DDH cases without cam deformity. Thus, it is essential to establish the co-existence of cam deformity, especially in cases of borderline DDH. In actual surgery, the joint capsule must be released to expose femoral head-neck junction to perform cam resection. In that case, the plication of the capsule after cam resection is essential. These procedures are relatively complicated and needs certain invasion. If there is no need to perform the cam resection, capsular release could be minimized. Therefore, it is important to predict whether the cam resection is effective or not preoperatively by virtual osteochondroplasty. While hip arthroscopy for severe DDH cases should be cautious $[21,23]$, performing the computer simulation of virtual osteochondroplasty may provide the positive reason for the cam resection in borderline DDH with cam deformity cases.

One of the limitations of this study is that we were unsure whether our models of osteochondroplasty were optimized for cam deformity in terms of resection depth, width, and length of the femoral headneck junction. Several studies reported "reasonable" resection areas for the femoral neck that would minimize the risk of femoral neck fracture; therefore, we were guided by these studies [18, 19]. While the clinical validity of this resection model needs to be considered, it was essential that we used standardized models of osteochondroplasty for computer simulation. Another limitation is that the influence of soft tissues, including the labrum, ligaments, and joint capsule, was not considered in the computer simulation. Further, the clinical important issue is that we could not measure actual clinical outcome after osteochodroplasty in all cases. The relationship between actual clinical outcomes and virtual surgery should be investigated. Regarding this point, we should note that it is impossible to argue the clinical outcomes only by improvement of ROM. However, Kemp et al. [24] reported that greater hip ROM was independently associated with better scores in several clinical outcomes including quality of life. Thus, the improvement of ROM should be one of the positive factors for getting satisfactory clinical outcomes.

\section{Conclusion}

In conclusion, virtual osteochondroplasty resulted in a significant improvement in internal rotation angle in cases of borderline DDH with cam deformity but not in cases of borderline DDH without cam deformity. Thus, careful consideration should be given to cam resection in cases of borderline DDH with cam deformity using computer simulation. Further studies are needed to validate the clinical outcome of patients with borderline DDH with cam deformity that undergo osteochondroplasty.

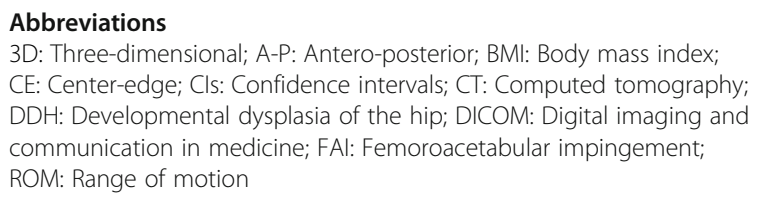

\section{Acknowledgments}

We thank Dr. Yohei Yukizawa, Dr. Hiroyuki Ike, Dr. Masaki Kawamura, Dr. Yoko Matsuda, and Dr. Takuma Naka for their valuable contributions to the current study.

Funding

There was no funding source.

Availability of data and materials

All of the data for this study are contained in the manuscript.

\section{Authors' contributions}

SK performed study design, acquisition of data, analysis and interpretation of data, preparation of manuscript. YI review the paper and revised the draft version. NK performed study design, analysis and interpretation of data, review the paper. $\mathrm{HC}$ and $\mathrm{TT}$ performed analysis and interpretation of data. TS review and revised final version of manuscript. All authors confirmed to approve of the final manuscript.

\section{Ethics approval and consent to participate}

This study was approved by the institutional review board at Yokohama City University. All the patients provided informed consent to participate in the study.

\section{Consent for publication}

Not applicable

Competing interests

The authors declare that they have no competing interests.

\section{Publisher's Note}

Springer Nature remains neutral with regard to jurisdictional claims in published maps and institutional affiliations.

Received: 22 June 2017 Accepted: 11 October 2017

Published online: 16 October 2017

\section{References}

1. Ganz R, Parvizi J, Beck M, Leunig M, Notzli H, Siebenrock KA. Femoroacetabular impingement: a cause for osteoarthritis of the hip. Clin Orthop Relat Res. 2003;417:112-20.

2. Beall DP, Sweet CF, Martin HD, Lastine CL, Grayson DE, Ly JQ, Fish JR. Imaging findings of femoroacetabular impingement syndrome. Skelet Radiol. 2005:34(11):691-701.

3. Beck M, Kalhor M, Leunig M, Ganz R. Hip morphology influences the pattern of damage to the acetabular cartilage: femoroacetabular impingement as a cause of early osteoarthritis of the hip. J Bone Joint Surg Br. 2005;87(7): 1012-8.

4. Philippon MJ, Maxwell RB, Johnston TL, Schenker M, Briggs KK. Clinical presentation of femoroacetabular impingement. Knee Surg Sports Traumatol Arthrosc. 2007;15(8):1041-7. 
5. Jacobsen S, Sonne-Holm S, Soballe K, Gebuhr P, Lund B. Hip dysplasia and osteoarthrosis: a survey of 4151 subjects from the Osteoarthrosis substudy of the Copenhagen City heart study. Acta Orthop. 2005;76(2):149-58.

6. Reijman M, Hazes JM, Pols HA, Koes BW, Bierma-Zeinstra SM. Acetabular dysplasia predicts incident osteoarthritis of the hip: the Rotterdam study. Arthritis Rheum. 2005;52(3):787-93.

7. Ida T, Nakamura Y, Hagio T, Naito M. Prevalence and characteristics of camtype femoroacetabular deformity in 100 hips with symptomatic acetabular dysplasia: a case control study. J Orthop Surg Res. 2014;9:93. doi: 10.1186/ s13018-014-0093-4.

8. Paliobeis $\mathrm{CP}$, Villar RN. The prevalence of dysplasia in femoroacetabular impingement. Hip Int. 2011;21(2):141-5.

9. Hufeland M, Kruger D, Haas NP, Perka C, Schroder JH. Arthroscopic treatment of femoroacetabular impingement shows persistent clinical improvement in the mid-term. Arch Orthop Trauma Surg. 2016:136(5):687-91.

10. Palmer DH, Ganesh V, Comfort T, Tatman P. Midterm outcomes in patients with cam femoroacetabular impingement treated arthroscopically. Arthroscopy. 2012;28(11):1671-81.

11. Domayer SE, Ziebarth K, Chan J, Bixby S, Mamisch TC, Kim YJ. Femoroacetabular cam-type impingement: diagnostic sensitivity and specificity of radiographic views compared to radial MRI. Eur J Radiol. 2011; 80(3):805-10.

12. Lohan DG, Seeger LL, Motamedi K, Hame S, Sayre J. Cam-type femoralacetabular impingement: is the alpha angle the best MR arthrography has to offer? Skelet Radiol. 2009;38(9):855-62.

13. Byrd JW, Jones KS. Hip arthroscopy in the presence of dysplasia. Arthroscopy. 2003;19(10):1055-60.

14. Notzli HP, Wyss TF, Stoecklin CH, Schmid MR, Treiber K, Hodler J. The contour of the femoral head-neck junction as a predictor for the risk of anterior impingement. J Bone Joint Surg Br. 2002;84(4):556-60.

15. Domb BG, Stake CE, Lindner D, El-Bitar Y, Jackson TJ. Arthroscopic capsular plication and labral preservation in borderline hip dysplasia: two-year clinical outcomes of a surgical approach to a challenging problem. Am J Sports Med. 2013;41(11):2591-8.

16. Kutty S, Schneider P, Faris P, Kiefer G, Frizzell B, Park R, Powell JN. Reliability and predictability of the centre-edge angle in the assessment of pincer femoroacetabular impingement. Int Orthop. 2012;36(3):505-10.

17. Kobayashi N, Inaba Y, Kubota S, Nakamura S, Tezuka T, Yukizawa Y, Choe H, Saito T. The distribution of impingement region in cam-type femoroacetabular impingement and borderline dysplasia of the hip with or without cam deformity: a computer simulation study. Arthroscopy. 2017; 33(2):329-34.

18. Alonso-Rasgado T, Jimenez-Cruz D, Bailey CG, Mandal P, Board T. Changes in the stress in the femoral head neck junction after osteochondroplasty for hip impingement: a finite element study. J Orthop Res. 2012;30(12):1999-2006.

19. Rothenfluh E, Zingg P, Dora C, Snedeker JG, Favre P. Influence of resection geometry on fracture risk in the treatment of femoroacetabular impingement: a finite element study. Am J Sports Med. 2012;40(9):2002-8.

20. Bedi A, Dolan M, Magennis E, Lipman J, Buly R, Kelly BT. Computer-assisted modeling of osseous impingement and resection in femoroacetabular impingement. Arthroscopy 2012;28(2):204-210.

21. Fukui K, Trindade CA, Briggs KK, Philippon MJ. Arthroscopy of the hip for patients with mild to moderate developmental dysplasia of the hip and femoroacetabular impingement: outcomes following hip arthroscopy for treatment of chondrolabral damage. Bone Joint J. 2015;97-b(10):1316-21.

22. Jayasekera N, Aprato A, Villar RN. Hip arthroscopy in the presence of Acetabular dysplasia. Open Orthop J. 2015;9:185-7.

23. Uchida S, Utsunomiya H, Mori T, Taketa T, Nishikino S, Nakamura T, Sakai A. Clinical and radiographic predictors for worsened clinical outcomes after hip arthroscopic Labral preservation and capsular closure in developmental dysplasia of the hip. Am J Sports Med. 2016;44(1):28-38.

24. Kemp JL, Makdissi M, Schache AG, Finch CF, Pritchard MG, Crossley KM. Is quality of life following hip arthroscopy in patients with chondrolabral pathology associated with impairments in hip strength or range of motion? Knee Surg Sports Traumatol Arthrosc. 2015;24(12):3955-61.

\section{Submit your next manuscript to BioMed Central and we will help you at every step:}

- We accept pre-submission inquiries

- Our selector tool helps you to find the most relevant journal

- We provide round the clock customer support

- Convenient online submission

- Thorough peer review

- Inclusion in PubMed and all major indexing services

- Maximum visibility for your research

Submit your manuscript at www.biomedcentral.com/submit

) Biomed Central 